\title{
X-ray Scanner for ODP Leg 204: Drilling Gas Hydrates on Hydrate Ridge, Cascadia Continental Margin
}

July 31, 2002 Progress Report

Barry Freifeld, Tim Kneafsey, Jacob Pruess, Paul Reiter, Liviu Tomutsa

Earth Sciences Division

Lawrence Berkeley National Laboratory 


\begin{abstract}
An x-ray scanner was designed and fabricated at Lawrence Berkeley National Laboratory to provide high speed acquisition of $\mathrm{x}$-ray images of sediment cores collected on the Ocean Drilling Program (ODP) Leg 204: Drilling Gas Hydrates On Hydrate Ridge, Cascadia Continental Margin. This report discusses the design and fabrication of the instrument, detailing novel features that help reduce the weight and increase the portability of the instrument. Sample x-ray images are included. The x-ray scanner was transferred to scientific drilling vessel, the JOIDES Resolution, by the resupply ship Mauna Loa, out of Coos Bay, Oregon on July 25. ODP technicians were trained in the instruments operation. The availability of the x-ray scanner at the drilling site allows real-time imaging of cores containing methane hydrate immediately after retrieval. Thus, imaging experiments on cores can yield information on the distribution and quantity of methane hydrates. Performing these measurements at the location of core collection eliminates the need for high pressures or low temperature core handling while the cores are stored and transported to a remote imaging laboratory.
\end{abstract}

\title{
1. Introduction
}

Calibrating estimates of hydrate and underlying free gas concentrations in submarine formations determined with geophysical remote sensing techniques is one of the major objectives of the Ocean Drilling Program (ODP) Leg 204: Drilling Gas Hydrates On Hydrate Ridge, Cascadia Continental Margin [ODP, 2002]. The ODP has deployed the JOIDES Resolution, a 143-meter long scientific drilling vessel owned by Overseas Drilling Limited to drill a transect of sites through the gas hydrate stability zone on the southern part of Hydrate Ridge on the Cascadia accretionary margin, offshore Oregon. To assist in the quantification of hydrates and determine hydrate-bearing sediment textural properties in recovered core, a shipboard x-ray imaging system was developed at Lawrence Berkeley National Laboratory (LBNL). The basis for using x-ray imaging to quantify methane hydrate abundance and distribution has been previously established by Tomutsa et al. [2002] and Freifeld et al [2002]. The x-ray core scanner provides state-of-the-art x-ray imaging capability in a field-deployable package. The system was designed to be light and compact, operating within the space constraints of the core laboratory on the JOIDES Resolution, Bridge Deck/Level 6.

\section{Instrument Details}

Our goal in fabricating a transportable x-ray imaging system was to match the capabilities of laboratory based systems in a portable package that is practical to operate at remote locations. The $\mathrm{x}$-ray scanner occupies a rectangular box, $1.37 \mathrm{~m}$ wide, $0.61 \mathrm{~m}$ deep, and $2.03 \mathrm{~m}$ high. Figures 1 and 2 show a schematic and a photograph of the x-ray system, respectively. The total weight of the x-ray core scanner, excluding the remote personal computer and x-ray power supply, is approximately 170 $\mathrm{kg}$. The scanner has two axes of motion: a linear axis that moves the $\mathrm{x}$-ray imaging gantry along the vertical core axis, and a rotary axis that controls the core angle to the x-ray optical path. Motion on both axes is actuated by computer-controlled servo motors operating through reduction planetary gears to achieve high torque and positioning accuracy. The maximum core length that can be inserted into the x-ray scanner is $165 \mathrm{~cm}$, although only $150 \mathrm{~cm}$ of available linear travel exists. As currently configured, the maximum core diameter is fixed at $7.5 \mathrm{~cm}$. The core size can be easily changed by installing appropriately sized shielding.

The x-ray source is a Picker Hot-Shot $110 \mathrm{KV}$ x-ray source with a $0.3 \mathrm{~mm}$ focal spot size. The imaging unit consists of a monochrome CCD mounted behind a Precise Optics cesium iodide image 
intensifier with a 6-inch input window. The CCD is a Sony XC-75 with a resolution of $768 \times 494$ pixels and a signal to noise ratio of $56 \mathrm{~dB}$. A high-resolution monochrome monitor provides realtime viewing of the x-ray images. Any camera or VCR that has an NTSC format input can be used to record the output for later review although resolution equal to the $\mathrm{CCD}$ is required to avoid image degradation. Digital processing of the images is performed with a National Instruments PCI-1409 10-bit frame grabber installed on a personal computer.

Because $\mathrm{x}$-rays passing through the center of the core are more attenuated than those passing through the edges (a consequence of the circular cross section), an aluminum compensator (Figure 3 ) designed to flatten the image intensity was installed in front of the image intensifier. The compensator permits better use of the dynamic range available in the x-ray imaging system. On the sides of the compensator are areas of constant thickness that serve as calibration points to permit normalization of the image intensity between images.

Figure 4 presents a view of the x-ray source, imager, and shielding. The three-piece shielding represents a novel arrangement that provides flexibility in the optical path, as well as a high degree of radiation safety. The shielding consists of a fixed half clamshell mounted on the x-ray imager, and concentric telescoping pieces mounted between the core barrel and the x-ray source. The shielding is fabricated from a sandwich of two $1.6 \mathrm{~mm}$ thick stainless steel layers encapsulating a $1.6 \mathrm{~mm}$ thick layer of lead. The stainless steel layers protect the user from touching the lead and maintain the structural integrity of the lead. The $1.6 \mathrm{~mm}$ lead provides sufficient attenuation of scattered $\mathrm{x}$-ray radiation to eliminate the need for additional shielding away from the $\mathrm{x}$-ray path. This arrangement of shielding has significantly reduced the amount of lead that is typically used to encapsulate $\mathrm{x}$-ray imaging systems. The reduced shielding affords the operator a clear view of the $\mathrm{x}$ ray system through a polycarbonate door, permitting viewing of the core angle and gantry position.

The ability to change the distance between the x-ray source and the image intensifier permits the system to accommodate different diameter cores. This flexibility in the x-ray path arises from the telescoping nature of the shielding mounted between the x-ray source and the core, permitting changes in the x-ray path length. The path length change is easily performed in the field by loosening mounting screws on the gantry track and sliding either the x-ray source, imager, or both. Similarly, changing the compensator to one optimized for a new diameter core is performed by removing the six set screws that attach it to the front of the image intensifier and replacing it.

The clamshell shielding arrangement uses alignment pins and two safety interlock switches that prevent operation of the x-ray source if the shielding is not properly closed. Each of the two interlock switches opens independent circuits, providing for redundancy in the event of a single component failure. The first interlock switch prevents the computer control system from turning on the $\mathrm{x}$-ray source. The second interlock switch prevents the $\mathrm{x}$-ray power supply from energizing the high voltage windings in the x-ray power supply. To further prevent users from getting near the shielding when the x-ray unit is activated, the shielding interlock switches are wired in series with interlock switches mounted on the polycarbonate door. This arrangement prevents the x-ray source from being energized when either the door is open or when the shielding is not properly closed.

The linear and rotary axes of motion provide flexibility in core imaging. The scanning software operates in two distinct modes: a linear scanning mode and a computed tomography (CT) mode. The linear scanning mode starts imaging at the top of the core. An initial image is acquired and then the core is rotated 90 degrees and a second image is acquired. The gantry holding the $\mathrm{x}$-ray optics is 
then lowered $10 \mathrm{~cm}$ and two more images are acquired with a 90-degree separation between images. This process is repeated until a total of 24 images of the core are collected. The entire process takes about two minutes. A CT scan can be conducted to acquire images for later 3-D reconstruction. The user enters into the computer the linear location along the core at which a series of $\mathrm{x}$-ray images is desired and the number of partial rotations that a full rotation of the core is to be subdivided into. A typical number of images would be 360, yielding an image for every degree of rotation.

Implementation of the 3-D reconstruction of the images in real time is being planned.

\section{Instrument Deployment}

The x-ray scanner was packed for shipment on July 22, and was trucked to Coos Bay, Oregon, for transfer to the JOIDES Resolution. The tugboat Mauna Loa, carrying the x-ray scanner and personnel, departed Coos Bay at 6 PM, July 23, and arrived at the JOIDES Resolution at daybreak on July 24. Barry Freifeld and Jacob Pruess from LBNL with assistance from Frank Rack (Staff Scientist, Joint Oceanographic Institutions), Brad Julson (Supervisor of Shipboard Laboratories), as well as several staff ODP technicians installed and set up the instrument, with these activities concluded by $11 \mathrm{AM}$ on the same day. Figure 5 shows a picture of the $\mathrm{x}$-ray scanner as installed in the JOIDES Resolution core laboratory. At 1 PM a training session was held to teach the ODP technicians how to use the instrument, with time for several technicians to perform scans on sample core. At 6 PM Barry Freifeld and Jacob Pruess were transferred to the Mauna Loa for transportation back to Coos Bay.

\section{Sample Images}

Sample images collected using the x-ray scanner include miscellaneous metallic objects, a core holder containing coarse sand and a test core containing oceanic sediments. Figure 6 shows a cross section of $1 / 4-20$ bolts and washers in a core holder surrounded by water-saturated Ottawa sand. The lower detail image in Figure 6 reveals the $1.27 \mathrm{~mm}$ pitch threads of a 1/4-20 bolt. A very close inspection of the threads shows that each thread face is sub-divided into four or five distinct pixels with strong contrast into the surrounding media. This image shows that the instrument is achieving the $0.3 \mathrm{~mm}$ resolution spot size, as specified by the x-ray source manufacturer.

Figure 7 is an image taken of the PVC coreholder (originally shown in Figure 6) at a location containing water-saturated sand. Two fine fractures are revealed, highlighting the ability of the core scanner to discern structural details that represent minute changes in sample density. These fractures represent planar features with similar orientation likely due to the orientation of the coreholder as it was loaded with small batches of loosely poured sand and water. Apparently, the moderate shaking applied by hand to the cylinder did not fully compact the sand into a uniform mass.

Figure 8 shows a test core used aboard the JOIDES Resolution that consists of a silty-clay oceanic sediment containing open fractures. Although the three dimensional topology of the fracture is not clearly shown by viewing a single two dimensional image, by watching the x-ray image of the core as it is scanned and rotated on the monitor, one can get a very good sense of the fractures 3-D features. Similarly, a digital 3-D CT reconstruction made from a series of rotational images can provide an accurate representation of the features morphology. 


\section{Discussion}

The X-ray core scanner has met the objective of implementing a transportable imaging system for the ODP Leg 204 Drilling Gas Hydrates On Hydrate Ridge, Cascadia Continental Margin. The xray scanner imaging system has achieved the $0.3 \mathrm{~mm}$ limiting resolution of the $\mathrm{x}$-ray source. The motion control system has proven to operate reliably with excellent repeatability. Initial operation of the system indicates that performance can meet or exceed that of much larger laboratory based x-ray systems. Since the x-ray scanner is optimized to image geologic core, fine-tuning of the system is expected to provide sensitivity superior to that of large medical imaging systems.

Since preservation of the core for later study requires elevated pressure or reduced temperature during transit and storage and thus poses a formidable challenge, establishing a drill-site-based laboratory is crucial for measuring representative properties of sediments containing methane hydrates. On-site analysis thereby eliminates the concerns associated with sample degradation and alteration that accompany transportation and preservation. An on-site x-ray scanner will permit a range of both passive and active imaging studies on hydrate-bearing cores. Passive studies include textural characterization and phase saturation estimation. Active core testing represents a wide open area of research, and may include relative permeability measurements, progressive dissociation studies and hydrate/sediment mixture phase stability in relationship to controlled parameters, such as temperature, pressure, and inhibitor concentration.

The X-ray scanner as described herein was constrained in the amount of initial testing by the fixed deliverable date required for fielding the instrument on ODP Leg 204 on the JOIDES Resolution. A complete investigation of the instruments sensitivity and resolution through its entire dynamic range of operation will be carried out when it returns to LBNL. Initial testing has shown that the compensator design that was implemented can be further improved. The tight schedule required for system production precluded complete engineering of x-ray beam path lengths and material attenuations. A compensator optimized for the anticipated geologic samples would improve image quality and system sensitivity. It is expected that by adding software for real-time 3D CT image reconstruction, the value of the system will be further increased for on-site core characterization and active testing.

\section{Acknowledgments}

This work was supported by the Assistant Secretary for Fossil Energy, Office of Natural Gas and Petroleum Technology, through the National Energy Technology Laboratory, under the U.S. Department of Energy, Contract No. DE-AC03-76SF00098. The authors acknowledge the careful reviews of this report by George Moridis and Curt Oldenburg. 


\section{References}

Freifeld, B.M., Kneafsey, T.J., Tomutsa, L., Stern, L.A., and Kirby, S.H., 2002, Use of Computed $\mathrm{X}$-Ray Tomographic Data for Analyzing the Thermodynamics of a Dissociating Porous Sand/Hydrate Mixture, $4^{\text {th }}$ International Conference of Gas Hydrates, Yokohama, Japan.

ODP, 2002. Leg 204 Scientific Prospectus, Drilling Gas Hydrates On Hydrate Ridge, Cascadia Continental Margin.

Tomutsa, L., Freifeld, B.M., Kneafsey, T.J., \& Stern, L.A., 2002. X-ray computed tomography observation of methane hydrate dissociation, Proceedings of the SPE 2002 Gas Technology Symposium, Calgary, Alberta, Canada. 


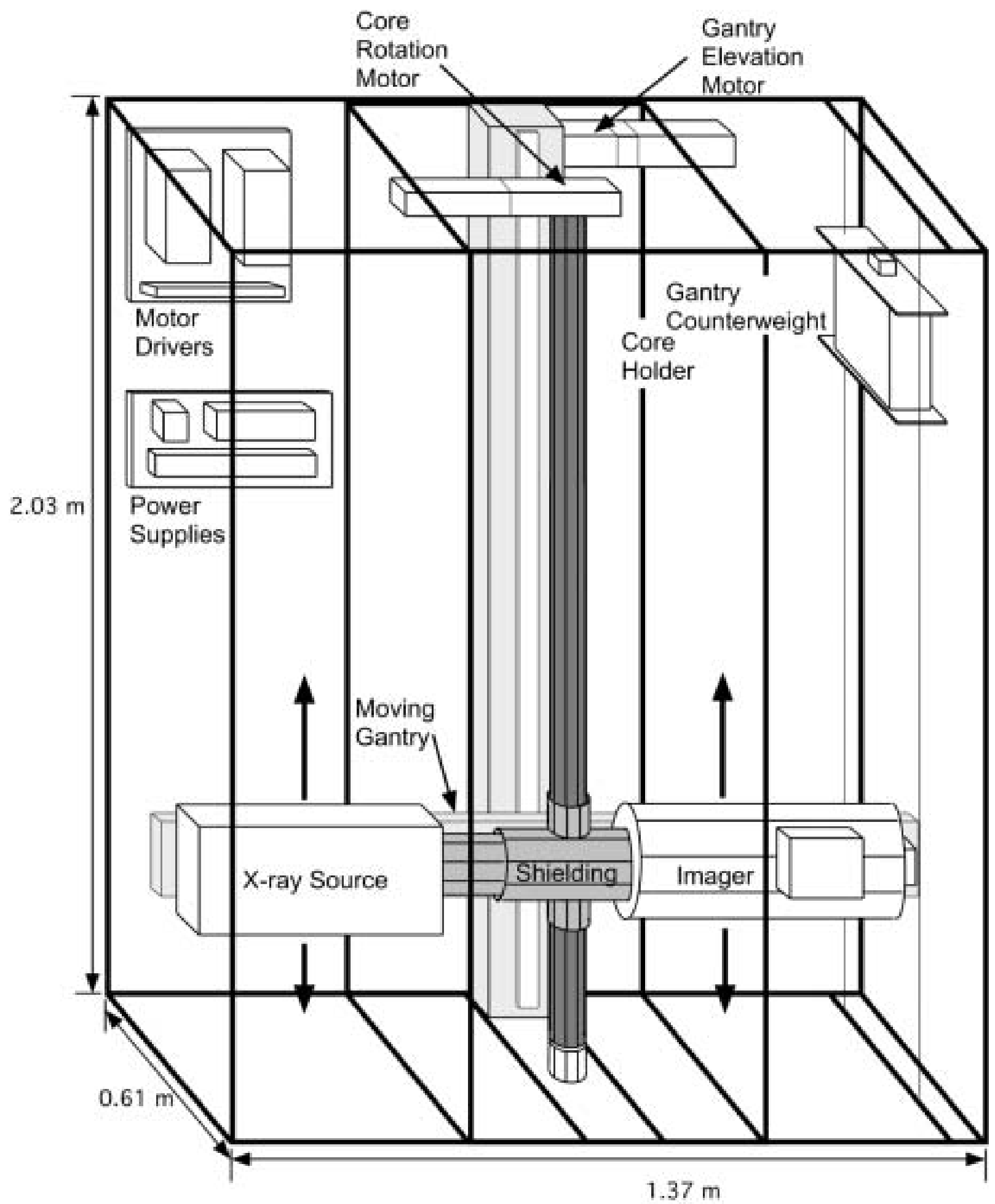

Figure 1. Schematic of the x-ray scanner showing the placement of major system components. 


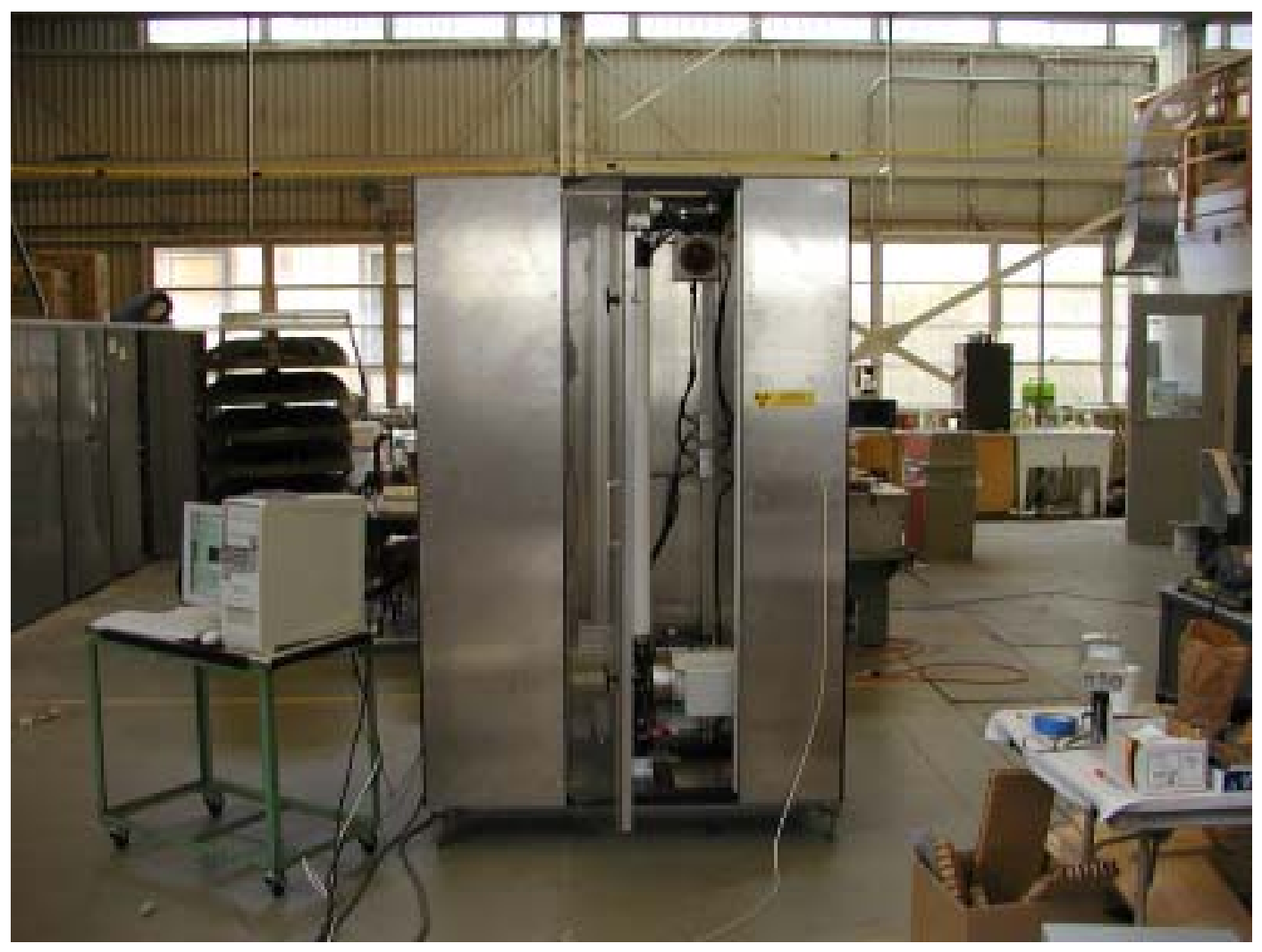

Figure 2. Picture of the x-ray scanner during testing at the LBNL. 


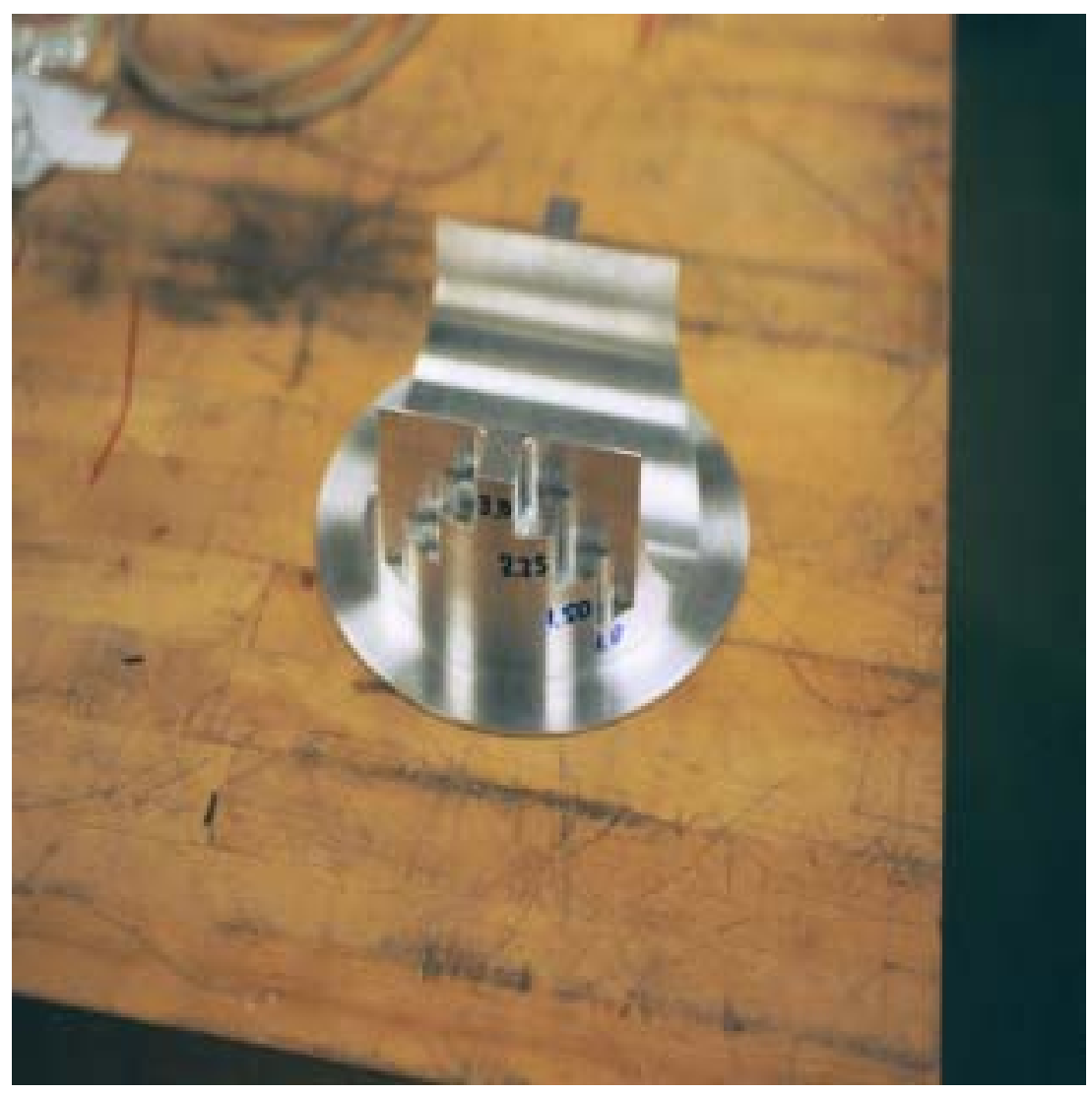

Figure 3. Aluminum x-ray compensator mounted in the front of the image intensifier. The curvature flattens the image intensity to account for the circular core cross section. The outer machined flats provide for calibration and normalization of x-ray beam intensity. 


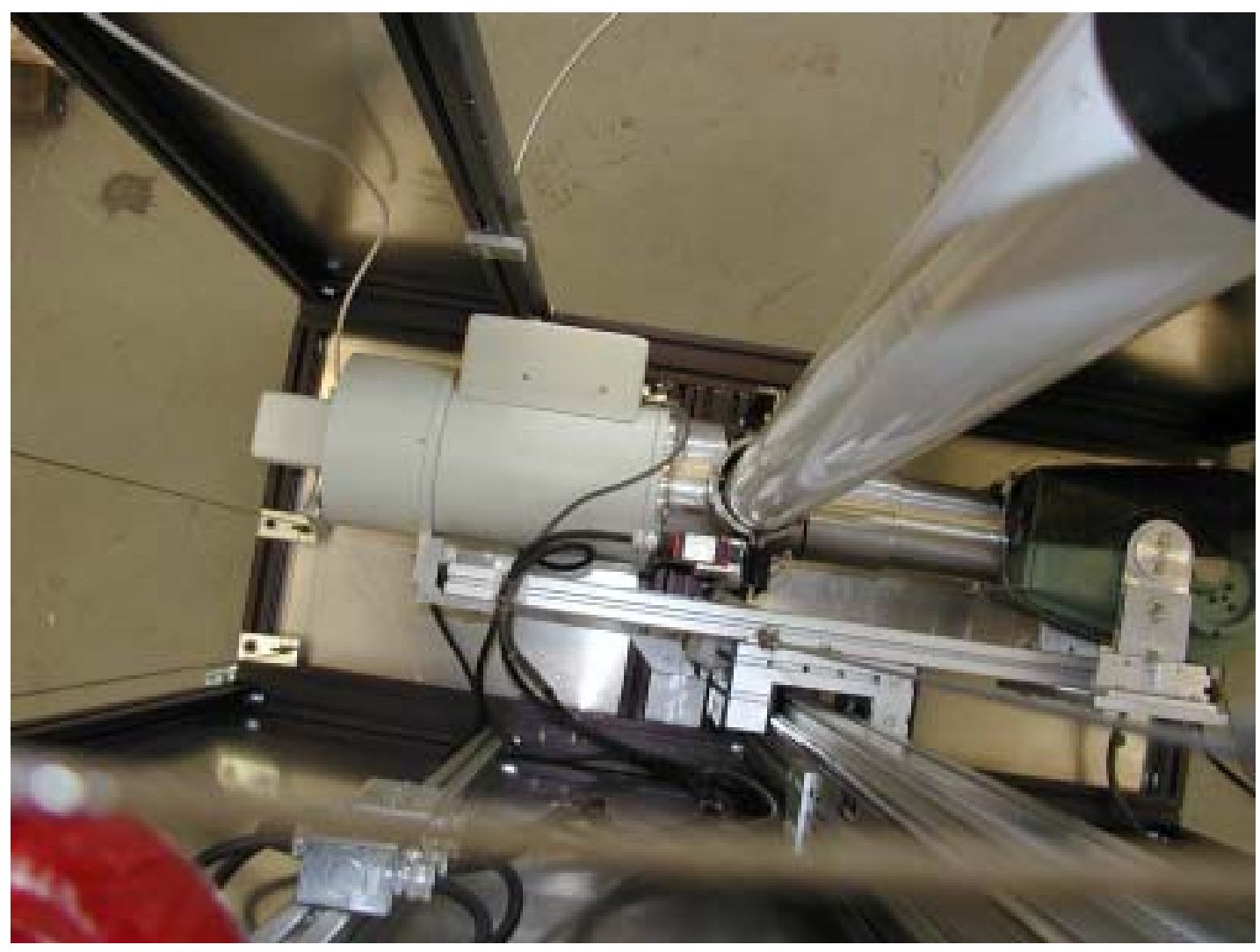

Figure 4. The x-ray beam path showing from left to right: CCD and image intensifier, $x$-ray shielding surrounding a PVC core holder, and the x-ray source. This picture was taken from the top of the x-ray scanner.

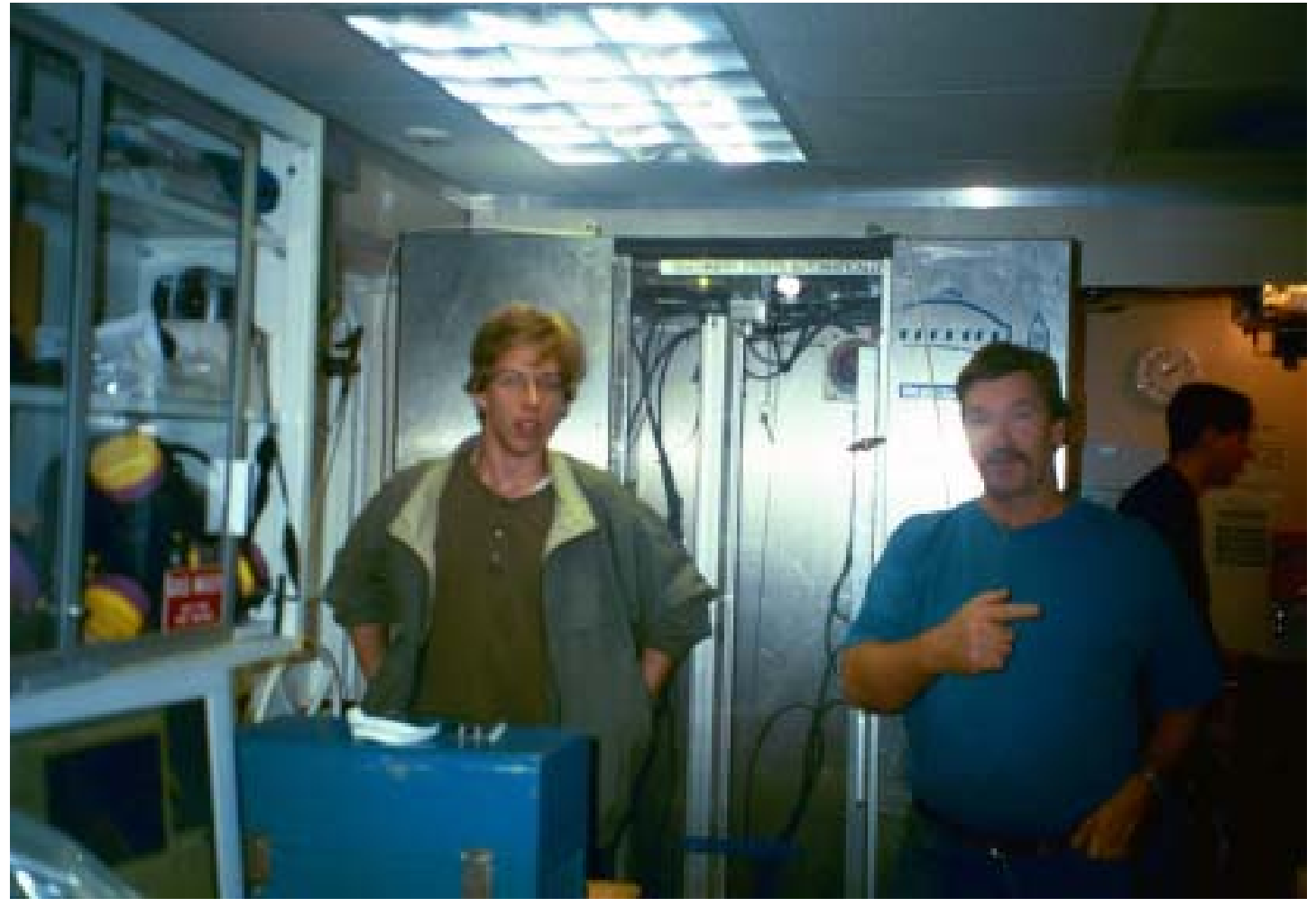

Figure 5. X-ray scanner being installed in the JOIDES Resolution core laboratory. From left to right is Jacob Pruess of LBNL and Brad Julson of ODP. 


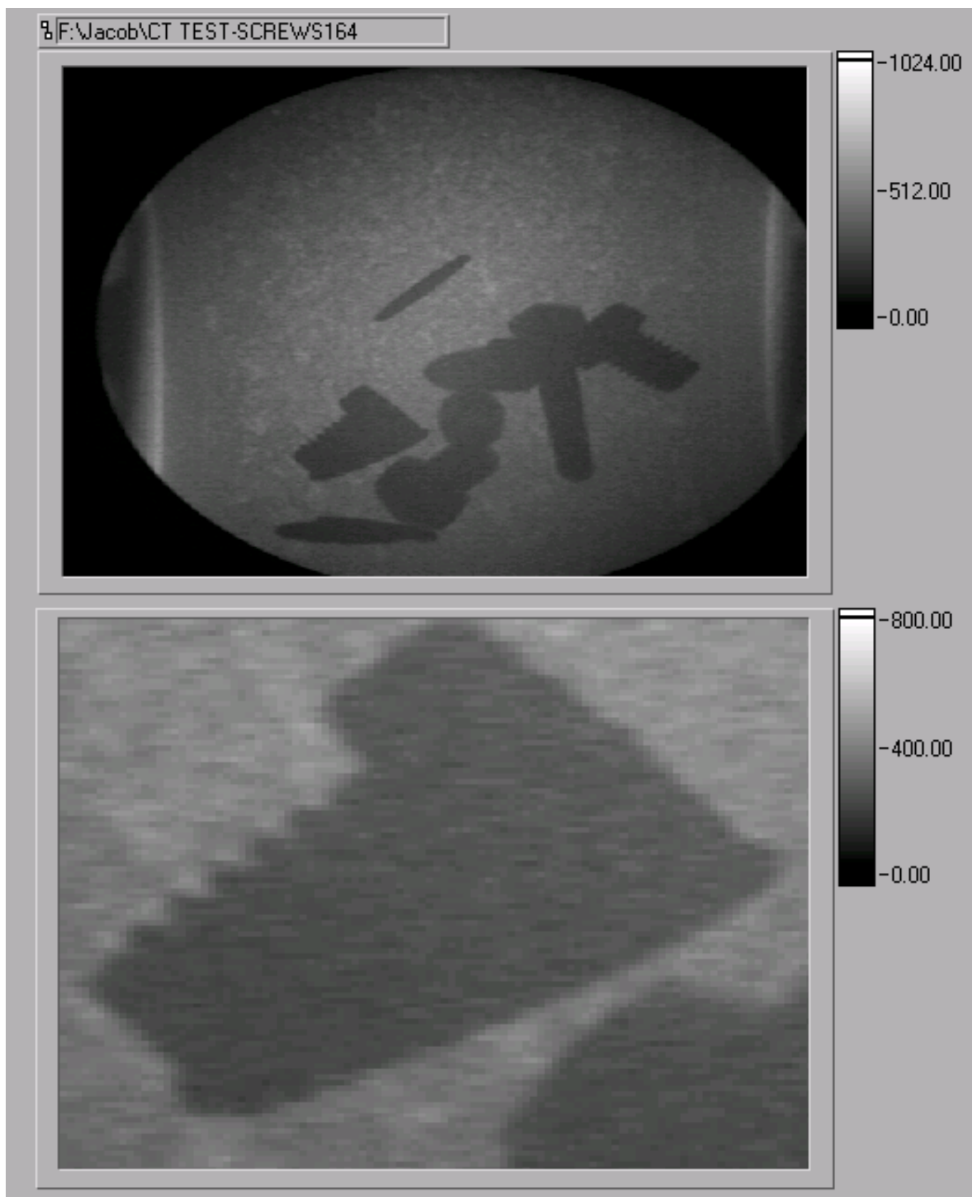

Figure 6. X-ray image of metallic screws and washers in a water saturated sand filled PVC core holder. The lower image has a close-up of a $1 / 4-20$ bolt $(1.27 \mathrm{~mm}$ pitch). The clarity of the threads indicate that the $x$-ray system attains a resolution equal to the $0.3 \mathrm{~mm}$ focal spot size of the $x$-ray source. 


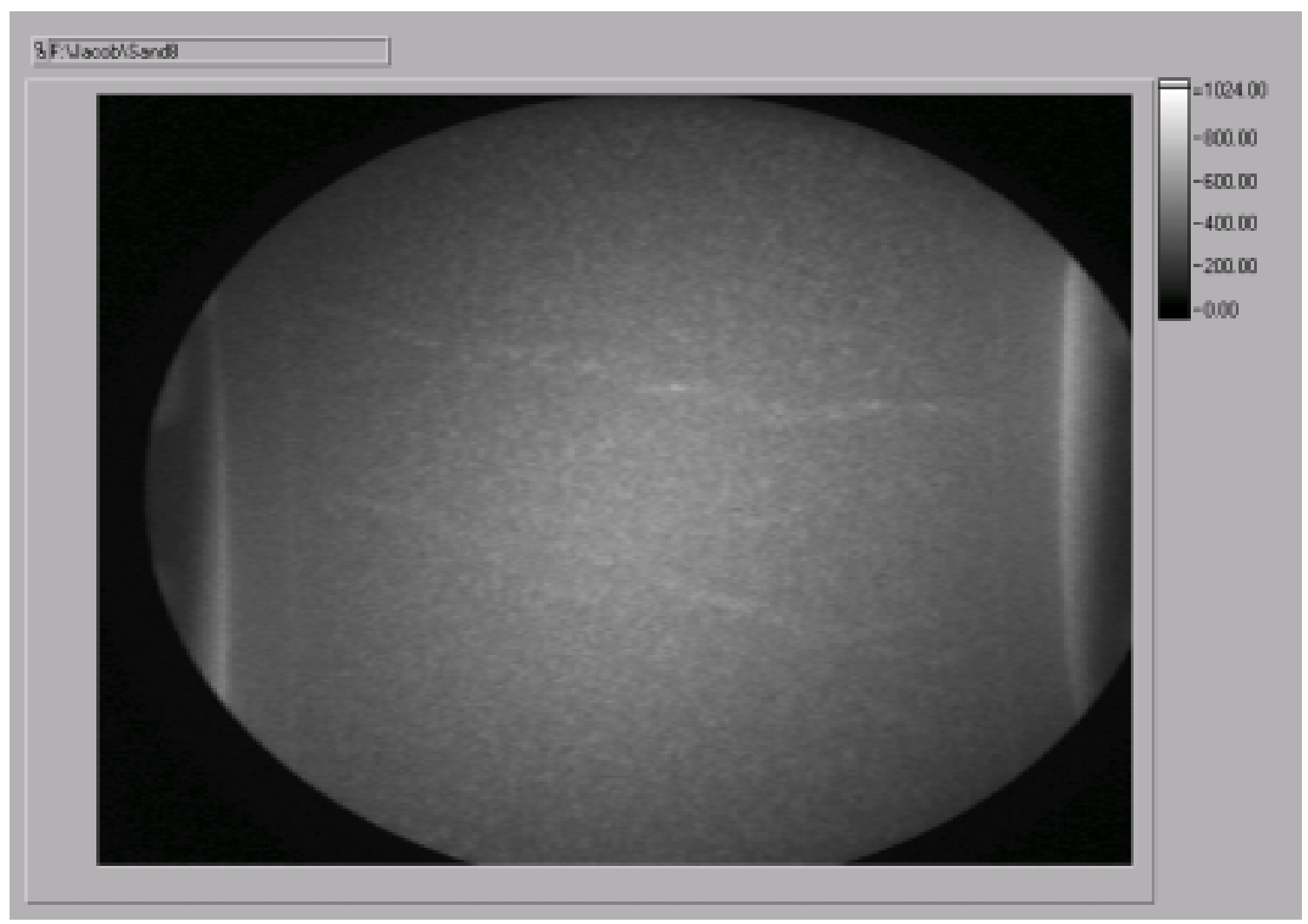

Figure 7. X-ray image of a core holder containing water-saturated Ottawa sand. The light sub-horizontal features are fractures in the otherwise homogeneous column. 


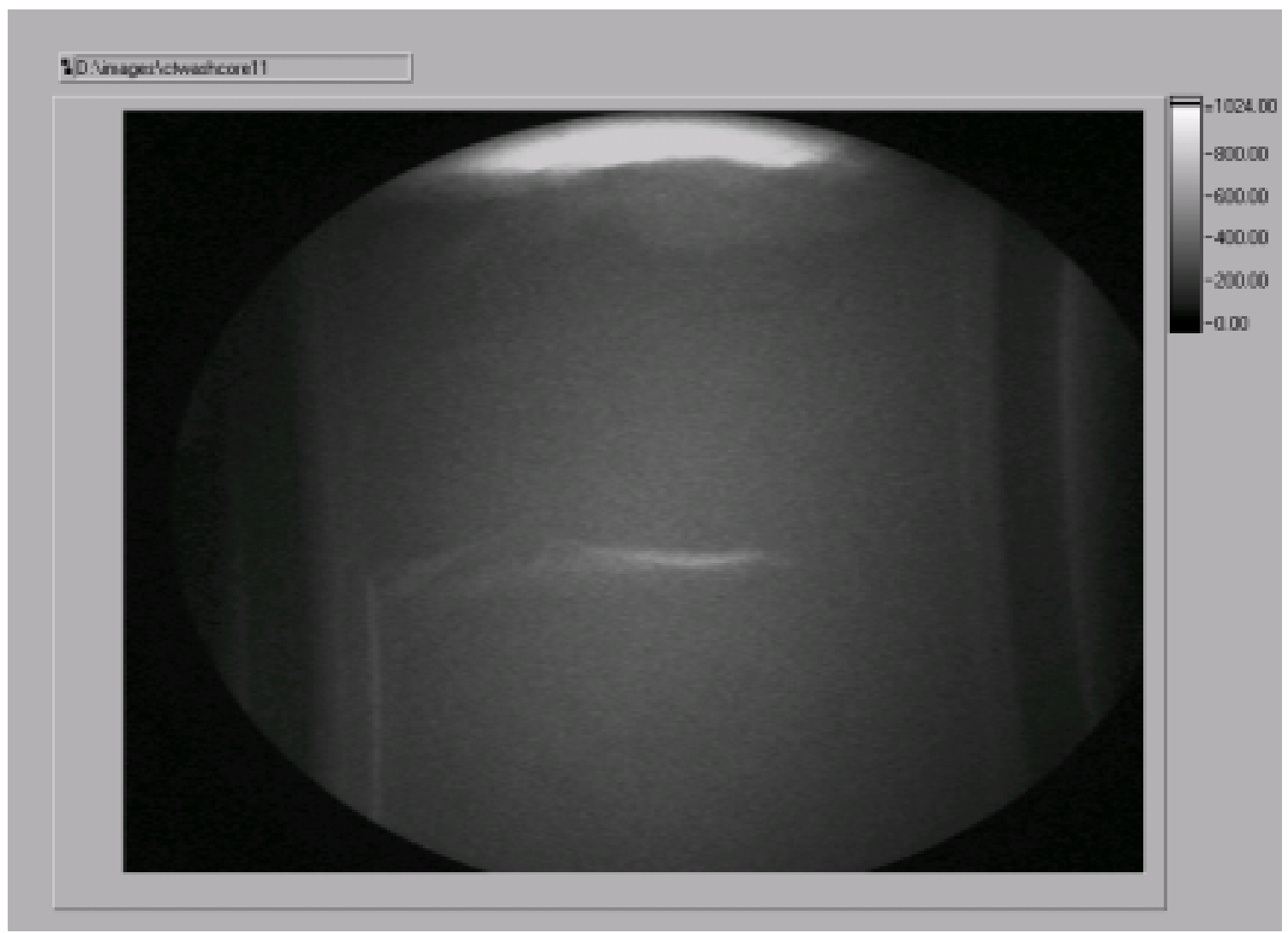

Figure 8. X-ray image taken aboard the JOIDES Resolution of silty-clay oceanic sediment showing a distinct horizontal fracture. 